\title{
New Possibilities in Thermal Analysis of Molding Materials
}

\author{
Judit Svidróa*, Attila Diószegi ${ }^{a}$ \\ a Jönköping University School of Engineering, Department of Materials and Manufacturing, Gjuterigatan 5 \\ Box 1026, SE-55111 Jönköping, Sweden \\ *e-mail: judit.svidro@ju.se
}

Received: 22 September 2018/Accepted: 7 December 2018/Published online: 22 December 2018

This article is published with open access by AGH University of Science and Technology Press

\begin{abstract}
Molding material-related studies within the research activities concerning foundry technology have always been limited despite the significant effect of molding mixtures on the quality of cast parts. One reason behind this trend is the difficulty in interpreting the results of such complex systems like molds and cores. This paper provides a new possibility for studying the heat-absorption performance of materials used as molding media in metal casting processes. By further developing the Fourier thermal analysis method of cores and molds introduced by earlier studies, the investigation of unbonded sand has become available. The heat-absorption properties of the components can be hereby separated and studied respectively. Thermal analyses were performed on sphere-shaped resin-bonded cores with various binder levels as well as on unbonded sand samples. The temperature data collected from two points of the samples were then used for the calculation of the novel thermophysical properties. The results revealed not only quantitative but qualitative differences in the characteristics of the binder decomposition processes, providing a deeper understanding on the thermal behavior of molding materials. The outcome of the research provides more accurate data, which is the key for the improved simulation of casting processes.
\end{abstract}

\section{Keywords:}

casting, foundry sand, Fourier thermal analysis, heat absorption, molding material, silica sand

\section{INTRODUCTION}

In the hot box process, a mixture of sand, furan, or phenolic thermosetting resin with a nitrate or chloride catalyst are blown into a heated core box. This is a quite rapid core-making method that provides good dimensional accuracy and is suitable for the serial production of cores used in iron, steel, or aluminum casting. The temperature of the tool $\left(220-240^{\circ} \mathrm{C}\right)$ ensures an approx. 30 s polymerization time and can vary depending on the geometry of the core, the composition of the mixture, and the type of resin used. The typical resin level is approx. $2 \%$ based on the weight of the sand, and the catalyst ratio is approx. $25 \%$ based on the weight of the resin.

The behavior of the most commonly used molding mixtures have been thoroughly studied by previous authors on various instruments [1-4]. However, the variety of organic binder systems is updated time and again based on customer requirements as well as economic and environmental considerations.

Besides the traditional experiments to determine mechanical properties of cores and molds, research interest has been focusing on the thermophysical behavior of the materials as well [5-8]. This is crucial for the prediction of the temperature field; therefore, it determines every parameter that affects the simulation result. Researchers have made intensive efforts to find solutions for reproducible in situ methods with improved accuracy; thus, there are many experimental layouts that can be found in the literature $[9,10]$.
However, the interpretation of results related to molding mixtures is complicated since the number of influencing factors is too high and it is difficult to determine the relationship between cause and effect. Molds and cores consist of base aggregates, binders, and additives, constructing a granulous porous system in which the refractory grains are connected to each other with binder bridges. During the casting process, the properties of each component changes as the temperature increases, resulting in unpredictable behavior of the mold. The measured parameter is, thus, an average of the whole system and cannot be referred to the components directly. To obtain a comprehensive understanding of molding materials, the problem of separating complex results needs to be solved.

Thermal analysis is a well-known and applied technique to monitor the solidification behavior of cast alloys. Svidro et al. [11] developed a novel application of thermal analysis to gain knowledge about the thermophysical properties of molding mixtures [12]. The calculated parameters are regarding mixtures; therefore, it is not possible to associate them with the various components of the core. With the purpose of obtaining more detailed results through the separation of various heat-absorbing phenomena, the development of the above-mentioned method [11] has been subjected. By means of this innovation, it is now possible to perform an in situ thermal analysis of unbonded foundry sands, which is a novel approach in the research of molding materials. This paper introduces the recent updates attained and the utilization possibilities of our experimental results. 


\section{MATERIALS AND MEASUREMENT METHODS}

The temperature of sphere-shaped samples with a diameter of $40 \mathrm{~mm}$ was measured during their immersion into molten aluminum. The two measuring points were on the horizontal center plane - one in the middle of the specimen, and the other $10 \mathrm{~mm}$ from the edge. The $\mathrm{N}$-type thermocouples were protected by quartz pipes that did not reach the measuring points, so the thermocouples were in direct contact with the sand and mixtures. Figure 1 shows an isometric view of the measurement layout.

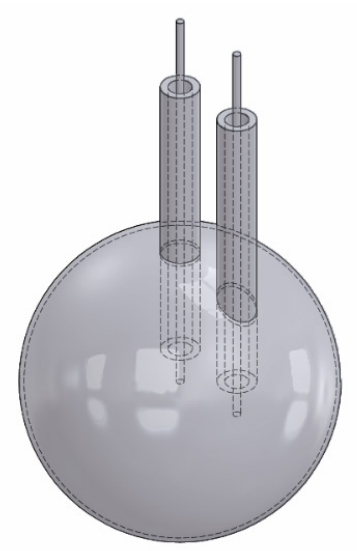

Fig. 1. Isometric view of measurement layout

Since unbonded sand samples would collapse without a binder, thin-walled containers made of aluminum-oxide were used for the experiments. The heat-absorbing properties of pure silica sand was studied and used as a reference point for furan hot-box mixtures with various resin levels. The base sand was the same type of foundry silica sand for all of the mixtures, as was the unbonded sample. This is a clean well-graded sand that consists of three main fractions; the grain-size distribution and cumulative mass passing through each sieve versus the sieve opening is shown in Figure 2. The shown granulometric properties were determined by a sieve analysis using ISO standard aperture sizes.

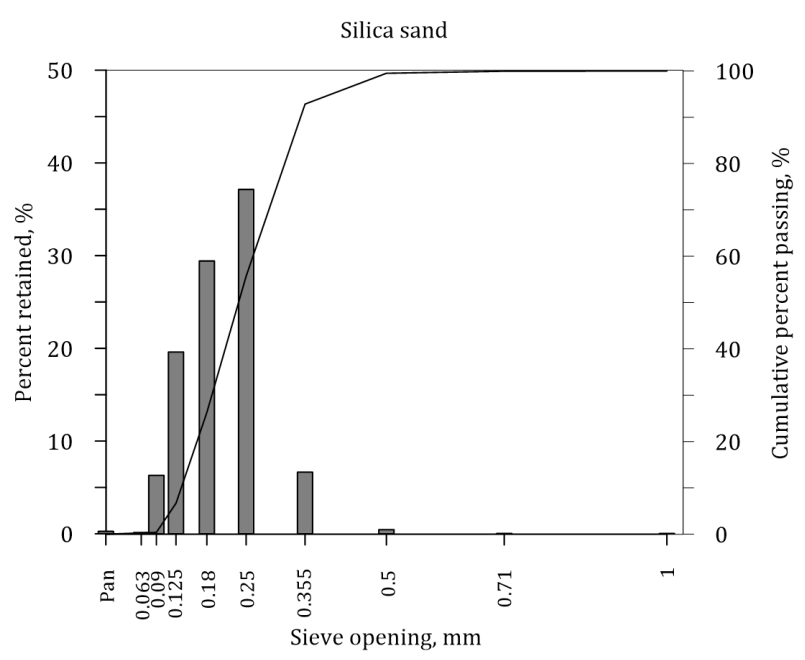

Fig. 2. Grain size distribution of studied silica sand
The composition of the studied materials is shown in Table 1. The studied hot-box binder system consists of a furan urea resin that is especially suitable for aluminum casting and a hardener that is an aqueous solution of inorganic acid salts (and also suitable for the manufacture of cores for light-metal casting). The mixing time was $1+1$ minutes with the hardener and then the resin, respectively. The mixture was blown into a core box heated to $200^{\circ} \mathrm{C}$. The samples were produced in a BENETLAB laboratory core shooter machine. To avoid differences in the experimental conditions, the resin-bonded cores were also coated with an aluminum-oxide layer. The bulk density was set to equal for all four specimens: $1.37 \pm 0.02 \mathrm{~g} / \mathrm{cm}^{3}$. The temperature of the aluminum melt was $680 \pm 10^{\circ} \mathrm{C}$.

Table 1

Composition of studied samples

\begin{tabular}{cc}
\hline $\begin{array}{c}\text { Binder content } \\
\text { based on weight } \\
\text { of sand, \% }\end{array}$ & $\begin{array}{c}\text { Hardener content } \\
\text { - based on weight } \\
\text { of resin, } \%\end{array}$ \\
\hline 0 & 0 \\
\hline 1 & 33 \\
\hline 2 & 33 \\
\hline 3 & 33 \\
\hline
\end{tabular}

There are major differences in the approach of this method and other common laboratory experiments. This layout is meant to reproduce conditions similar to the casting process where the molding material is in direct contact with the melt. It also provides higher heating rates when compared to that which is achievable in laboratory devices (like DSC, DTA, LFA, or muffle furnaces). Additionally, the sphere shape has essential importance in calculating the of thermophysical properties, since the temperature gradient is homogenous in this geometry. The rates of heat absorption versus temperature were determined by a Fourier thermal analysis. The temperature data was evaluated by an iteration algorithm based on the heat-conduction equation explained in a previous paper [11].

\section{RESULTS AND DISCUSSION}

The main results of the calculations are the rates of heat absorption versus temperature in the center of the sample. This attribute describes the energy absorbed by a unit mass of the molding mixture versus time in addition to the energy consumed to raise the temperature of a unit mass of the material. Figure 3 shows the results of the three mixtures with different resin levels. The peaks indicate heat-absorbing processes like moisture evaporation, resin decomposition, and the allotropic transition of quartz. A previous author studied the degradation process of a hot-box furan binder system in a simultaneous thermal analyzer both in oxygen and oxygen-free atmospheres and found evidence of a similar multi-stage decomposition [13]. It is considered to have mixed atmospheric circumstances inside the spherical samples during the measurement; 
oxygen is present in the pores at the beginning of the experiment, which is continuously displaced by water vapor and the gases evolving from the decomposing binder. However, the main steps of the degradation process occur within similar temperature ranges as in both cases of the previous work (at approx. $180^{\circ}$ and $300^{\circ} \mathrm{C}$ ).

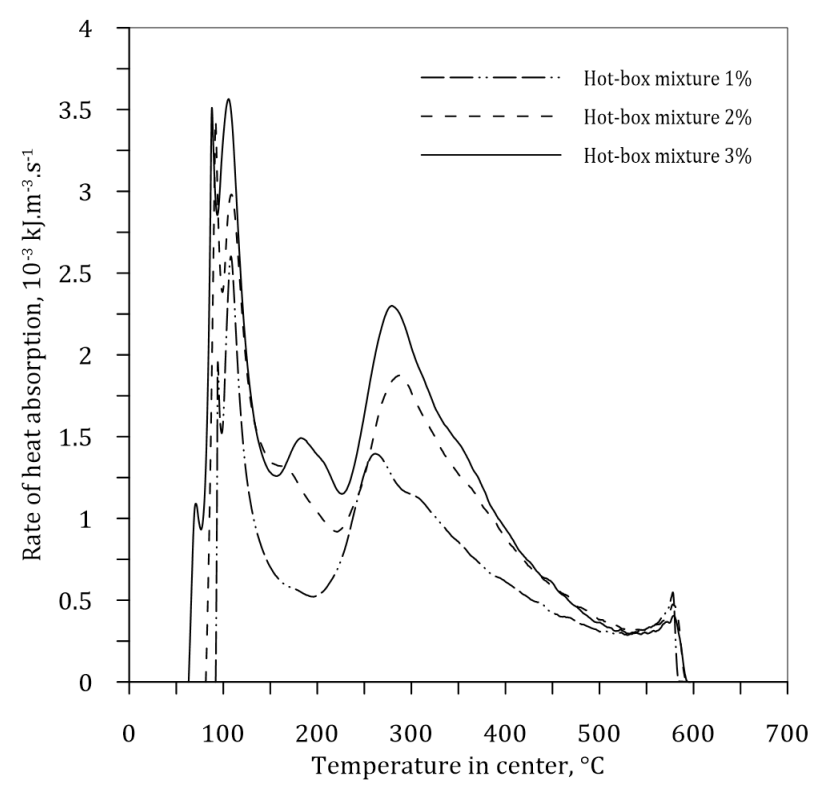

Fig. 3. Rate of heat absorption of hot-box mixtures with different resin content versus temperature

A comparison of the pure sand and the mixture with 2\% resin is shown in Figure 4. In the unbonded sand, only two significant processes can be observed. The first one is related to the evaporation of the water content of the sand above $100^{\circ} \mathrm{C}$. The second peak is apparently due to the $\alpha$-quartz to $\beta$-quartz transition at $573^{\circ} \mathrm{C}$. The heat absorption of the mixture is more complex, with several peak values that show the multi-stage decomposition of the resin.

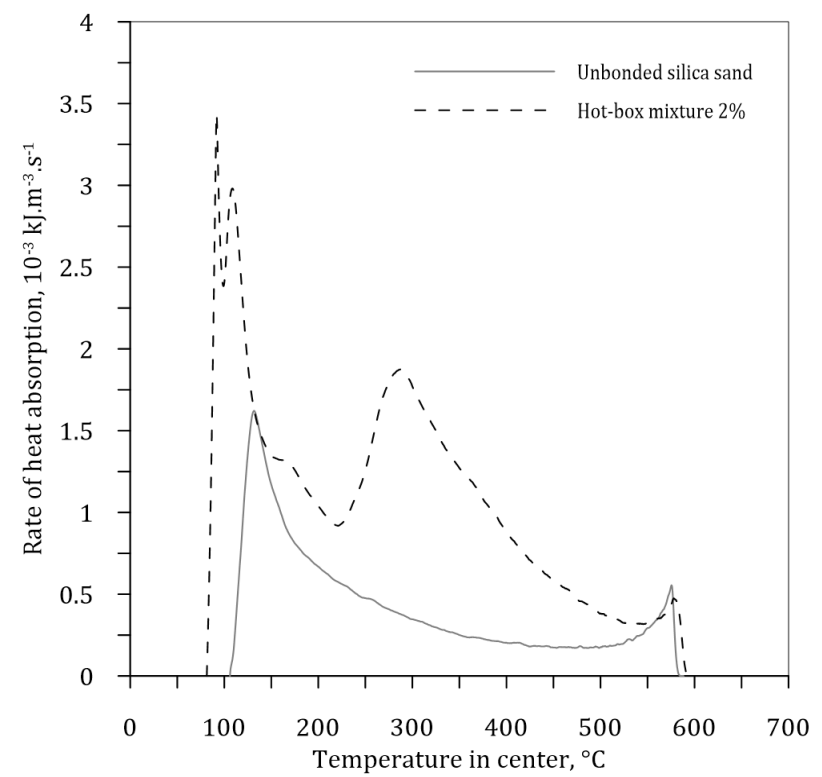

Fig. 4. Rate of heat absorption of unbonded and resin bonded samples versus temperature
The major benefit of being able to investigate pure sand in its unbonded form is that it can be utilized in the interpretation of the results collected from bonded mixtures.

By means of the result of unbonded sand, it is possible to determine the binder decomposition process of the hot-box system directly. Subtracting the data regarding the pure sand from the results of the mixture, the heat-absorption rate of the polymerized binder can be obtained (Fig. 5).

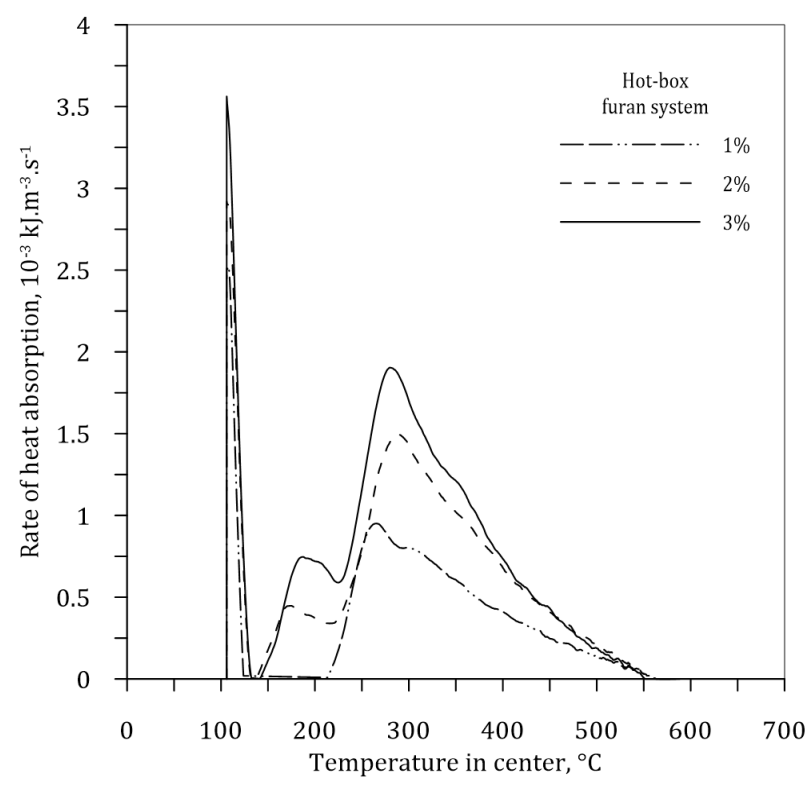

Fig. 5. Rate of heat absorption of hot box furan systems versus temperature

The curves also show that the energy needed for decomposition increases with the addition of resin. However, the values of the particular maximum peaks are not in a linear relationship. Furthermore, the second step of the decomposition (at around $200^{\circ} \mathrm{C}$ ) has no significant influence on the heat-absorbing properties below a certain level of resin content, as it is overlapped by the effect of the base sand within that temperature range. Regardless of the resin level, the degradation of hot-box furan system is completed by the time the temperature reaches $550^{\circ} \mathrm{C}$.

\section{CONCLUSION}

The unique thermal analysis technique used for the examination of molds and cores has been refined. The opportunity to investigate unbonded aggregates provides a new approach to the evaluation of thermal analysis results.

Studying different levels of binders highlighted the fact that, although a higher resin content causes higher heat absorption, it affects the heat-absorbing characteristics as well. By collecting the thermophysical properties of the main ingredients, it is possible to virtually build up any kind of molding mixture combinations (component by component). With the help of such a database, not only is a more accurate simulation is achievable, but one's customized needs can be fulfilled. 


\section{Acknowledgements}

The present work was financed by the Swedish Knowledge Foundation. The cooperating parties in the project were Jönköping University, Scania CV AB, and Volvo Powertrain Production Gjuteriet AB. The participants from these institutions and companies are gratefully acknowledged.

\section{REFERENCES}

[1] Nowak D. (2017). Determination of binder content in traditional sandmixes by microwave method. Journal of Casting \& Materials Engineering, 1(4), 80-84. Doi:10.7494/ jcme.2017.1.4.80.

[2] Stachowicz M., Paduchowicz P. \& Granat K. (2017). Impact of density degree and grade of inorganic binder on behavior of molding sand at high temperature. Journal of Casting \& Materials Engineering, 1(3), 64-69. Doi: 10.7494/jcme.2017.1.3.64.

[3] Holtzer M., Żymankowska-Kumon S., Kmita A. \& Dańko R. (2015). Emission of BTEX and PAHs from molding sands with furan cold setting resins containing different contents of free furfuryl alcohol during production of cast iron. China Foundry, 12(6), 446-450.

[4] Renhe H., Hongmei G., Yaoji T. \& Qingyun L. (2011). Curing mechanism of furan resin modified with different agents and their thermal strength. China Foundry, 8(2), 161-165.

[5] Grabowska B., Kaczmarska K., Bobrowski A., Żymankowska-Kumon S., Kurleto-Kozioł Ż. (2017). TG-DTG-DSC, FTIR, DRIFT, and Py-GC-MS studies of thermal decomposition for poly(sodium acrylate)/dextrin (PAANa/D) - new binder BioCo3. Journal of Casting \& Materials Engineering, 1(1), 27-32. Doi:10.7494/jcme.2017.1.1.27.

[6] Grabowska B., Malinowski P., Szucki M. \& Byczyński L. (2016). Thermal analysis in foundry technology. Journal of Thermal Analysis and Calorimetry, 126(1), 245-250. Doi:10.1007/ s10973-016-5435-5.
[7] Grabowska B., Hodor K., Kaczmarska K., Bobrowski A., Kurleto-Kozioł Ż. \& Fischer C. (2017) Thermal analysis in foundry technology: Part 2. TG-DTG-DSC, TG-MS and TG-IR study of the new class of polymer binders BioCo. Journal of Thermal Analysis and Calorimetry, 130(1), 301-309. Doi:10.1007/ s10973-017-6506-y.

[8] Malherbe G., Henry J.-F., El Bakali A., Bissieux C. \& Fohanno S. (2012). Measurement of thermal conductivity of granular materials over a wide range of temperatures. Comparison with theoretical models. 6th European Thermal Sciences Conference (Eurotherm 2012). Journal of Physics: Conference Series, 395. Doi:10.1088/1742-6596/395/1/012081.

[9] Solenicki G., Budic I. \& Ciglar D. (2010). Determination of thermal conductivity in foundry mould mixtures. Metalurgija, 49(1), 3-7.

[10] Zych J. \& Mocek J. (2015). Destruction of moulding sands with chemical binders caused by the thermal radiation of liquid metal. Archives of Foundry Engineering, 15(4), 95-100. Doi: 10.1515/afe-2015-0087.

[11] Svidró J.T., Diószegi A. \& Tóth J. (2014). The novel application of Fourier thermal analysis in foundry technologies. Examination of degradation characteristics in resin-bound moulding materials. Journal of Thermal Analysis and Calorimetry, 115(1), 331-338. Doi: 10.1007/s10973-013-3289-7.

[12] Svidró J.T., Diószegi A., Svidró J. \& Ferenczi T. (2017). The effect of different binder levels on the heat absorption capacity of moulding mixtures made by the phenolic urethane cold-box process. Journal of Thermal Analysis and Calorimetry, 130(3), 1769-1777. Doi:10.1007/s10973-017-6611-y.

[13] Łucarz M. (2015). Setting temperature for thermal reclamation of used moulding sands on the basis of thermal analysis. Metalurgija, 54(2), 319-322. 